\title{
Diferentes fontes de P no desenvolvimento do meloeiro e disponibilidade de fósforo no solo ${ }^{1}$
}

\author{
Use of biofertilizantes phosphated of the development of the melon and readiness of \\ phosphorus
}

\author{
Michelangelo de Oliveira Silva ${ }^{2 *}$, Newton Pereira Stamford ${ }^{3}$, Laerte Bezerra de Amorim ${ }^{4}$, Agenor Bezerra de \\ Almeida Júnior ${ }^{5}$ e Monikely de Oliveira Silva ${ }^{6}$
}

\begin{abstract}
Resumo - Avaliou-se o desenvolvimento da cultura do melão, como também a disponibilidade de fósforo nos solos com o uso de biofertilizante fosfatado após três ciclos da cultura. Os tratamentos foram distribuídos em blocos casualizados com três repetições, arranjados num fatorial $2 \times 3 \times 7$, correspondente a dois tipos de solos (Latossolo Amarelo e Neossolo Flúvico); três fontes de fósforo (superfosfato triplo, biofertilizante fosfatado e a rocha fosfatada; e sete níveis de fósforo $(0 ; 0,5 ; 1,0 ; 1,5 ; 2,0 ; 2,5 ; 3,0$ do recomendado para a cultura e para cada solo). Os fertilizantes superfosfato triplo, biofertilizante de rocha fosfatada e rocha fosfatada não apresentaram diferenças significativas na produção de matéria seca, porém o biofertilizante foi o que mais disponibilizou P nos dois solos estudados após três ciclos da mesma cultura.
\end{abstract}

Palavras-chaves - Melão. Teor de Fósforo. Conteúdo de Fósforo. Fertilizantes Fosfatados.

\begin{abstract}
This work assessed the development of melon crops,and the availability of phosphorus in the soil with the use of biofertilizer phosphate after three cycles of culture. The treatments were distributed into randomized block design with three repetitions, arranged in a factorial $2 \times 3 \times 7$, corresponding to two types of soils (Yellow Latossol and Fluvic Neosol); three sources of phosphorus (triple superphosphate, bio-fertilizer phosphate and rocks) and seven levels of phosphorus $(0 ; 0.5 ; 1.0 ; 1.5 ; 2.0 ; 2.5 ; 3.0$ of recommended for the culture and for each soil). The triple superphosphate fertilizer, biofertilizer rock phosphate and rock phosphate showed no significant differences in dry matter production, but the biofertilizer was the most available $\mathrm{P}$ in both soils after three cycles of the same culture.
\end{abstract}

Key words - Melon. Tenor phosphorus. Phosphorus content. Phosphated fertilizer.

\footnotetext{
* Autor para correspondência

${ }^{1}$ Recebido para publicação em 01/10/2009; aprovado em 28/02/2011

Trabalho da disciplina de Microbiologia do Solo para obtenção de créditos, recursos advindos do custeio do programa de Pós-Graduação em Ciência do Solo da UFRPE, e CNPq

${ }^{2}$ Programa de Pós-Graduação em Ciência do Solo/UFRPE, Recife-PE, Brasil, angelo ufrpe@yahoo.com.br

${ }^{3}$ Universidade Federal Rural de Pernambuco, Av. D. Manoel de Medeiros, s/n, Recife-PE, Brasil, 52.171-900, newton@depa.ufrpe.br

${ }^{4}$ Programa de Pós-Graduação em Tecnologias Energéticas e Nucleares da UFPE, Recife-PE, Brasil, laerteamorim@yahoo.com.br

${ }^{5}$ Programa de Pós-Graduação em Ciência do Solo/UFRPE, Recife-PE, Brasil, agenor_almeida@hotmail.com

${ }^{6}$ Graduanda em Administração Rural/UFERSA, Mossoró-RN, Brasil, monikelyufersa@yahoo.com.br
} 


\section{Introdução}

Nos últimos anos, a produção de melão (Cucumis melo L.) no Brasil tem aumentado substancialmente, sendo a região Nordeste a principal produtora, contribuindo com mais de $95 \%$ da produção nacional (IBGE, 2009). Nesse contexto, o estado do Rio Grande do Norte, destaca-se como o principal produtor e exportador dessa cucurbitácea, devido esse apresentar condições edafoclimáticas favoráveis a cultura.

Dado o avanço no cultivo do meloeiro e sua importância para a agricultura brasileira, se faz necessário o uso de tecnologias adequadas para aumentar a produtividade e melhorar a qualidade de frutos. A alta produtividade com frutos de boa qualidade está intrinsecamente ligado a uma adubação adequada. Dentre os nutrientes importantes para o desenvolvimento satisfatório do meloeiro destaca-se o fósforo (AMORIM et al., 2008), devido à influência na fase reprodutiva da planta, aumentando o número de frutos e o teor total de sólidos solúveis (NEGREIROS et al., 2003).

A expansão das áreas agrícolas e a demanda crescente de alimentos, junto com o esgotamento em nutrientes, requerem a prática da adubação, comaplicação de grandes quantidades de fertilizantes. As fontes fosfatadas requerem altos custos de beneficiamento para ser transformada em fertilizantes mais solúveis (GOEDERT; SOUSA, 1986; STAMFORD, et al., 2003), entretanto, essa transformação requer apreciável gasto de energia e mão de obra especializada (LIMA et al., 2007), além da necessidade de se estabelecer estratégias para o uso eficiente e econômico das rochas fosfáticas.

No contexto atual da agricultura irrigada, tem-se observado destaque cada vez maior para os chamados biofertilizantes, ou fertilizantes organominerais, que são produzidos através da inoculação de microrganismos em resíduos das mais diversas naturezas (STAMFORD et al., 2004a). A reciclagem de resíduos orgânicos, visando ao seu reaproveitamento como fonte alternativa para produção de fertilizantes, é uma medida extremamente estratégica, do ponto de vista ambiental, e por demais convenientes quando economicamente viável.

Considerando que os solos brasileiros são deficientes em fósforo e que os fosfatos são recursos naturais não renováveis (ARAÚJO et al., 2008; LEÃO et al., 2007), há necessidade em utilizá-lo eficientemente. A crescente conscientização ambiental nos últimos anos, e, principalmente, a escassez de matéria-prima para produção de fertilizantes minerais, despertou o interesse em vários pesquisadores (LIMA 2005; MOURA,
2007; STAMFORD et al., 2004b), em estudar outras fontes de fertilizantes agrícolas fosfatados, como por exemplo, a utilização de rochas fosfatadas e potássicas e a produção de biofertilizantes na agricultura.

Nesse sentido o trabalho tem como objetivo avaliar o desenvolvimento da cultura do melão, e a disponibilidade de fósforo em dois solos do Rio Grande do Norte com o uso de superfosfato triplo, biofertilizante fosfatado e rocha fosfatada após três ciclos da cultura.

\section{Material e métodos}

\section{Montagem e delineamento experimental}

O experimento foi conduzido em casa-devegetação, na Universidade Federal Rural do SemiÁrido (UFERSA), localizada no Município de Mossoró, Rio Grande do Norte (RN), Brasil, entre os meses de março a setembro de 2005 . O trabalho foi realizado em três ciclos, sendo cada ciclo conduzido até o início da frutificação, isto é, até os 45 dias após o plantio (DAP).

Os solos foram coletados a uma profundidade de 0 a $20 \mathrm{~cm}$ no Rio Grande do Norte, sendo o Latossolo Amarelo em Mossoró e o Neossolo Flúvico em Ipanguaçu. Parte desse solo foi seco ao ar, destorroado e peneirado em malha de $2 \mathrm{~mm}$ para obtenção da terra fina seca ao ar (TFSA), depois analisados quanto aos atributos químicos e físicos dos solos (TAB. 1), conforme metodologia da Embrapa (1999), enquanto a outra parte foi passada em malha de $4 \mathrm{~mm}$ para a instalação do experimento. Depois de peneirados, os solos foram colocados em vasos de $10 \mathrm{~L}$ e umedecidos com água destilada, até atingir a capacidade de saturação.

O delineamento experimental foi em blocos casualizados com três repetições, em esquema fatorial $2 \mathrm{x}$ $3 \times 7$, no total de 126 parcelas experimentais, cada parcela foi constituída de um vaso de capacidade de $10 \mathrm{~L}$ e uma planta por vaso. Foram utilizados dois tipos de solos (Latossolo Amarelo Distrófico psamítico e Neossolo Flúvico Eutrófico típico); três fontes de fósforo (Superfosfato triplo (SFT), Biofertilizante Fosfatado (BF) e o Rocha Fosfatada (RF); e sete níveis de fósforo $(0 ; 0,5 ; 1,0 ; 1,5 ; 2,0 ; 2,5$ e 3,0 vezes do recomendado para a cultura e para cada solo). A produção do biofertilizante foi a partir de uma rocha fosfatada com predominância do mineral apatita (apatita de Irecê, Bahia, com $24 \%$ de $\mathrm{P}_{2} \mathrm{O}_{5}$ ). 
Tabela 1 - Atributos químicos e físicos dos solos antes da montagem do experimento

\begin{tabular}{|c|c|c|}
\hline \multirow[b]{2}{*}{ Atributos } & \multicolumn{2}{|c|}{ Solos } \\
\hline & $\begin{array}{c}\text { Latossolo } \\
\text { Amarelo }\end{array}$ & $\begin{array}{c}\text { Neosssolo } \\
\text { Flúvico }\end{array}$ \\
\hline $\mathrm{pH}(1: 2,5)$ & 5,40 & 7,10 \\
\hline $\mathrm{CO}\left(\mathrm{g} \mathrm{kg}^{-1}\right)$ & 4,30 & 8,60 \\
\hline $\mathrm{N}\left(\mathrm{g} \mathrm{kg}^{-1}\right)$ & 12,90 & 24,50 \\
\hline $\mathrm{Ca}\left(\mathrm{cmol}_{\mathrm{c}} \mathrm{dm}^{-3}\right)$ & 0,90 & 12,00 \\
\hline $\mathrm{Mg}\left(\mathrm{cmol}_{\mathrm{c}} \mathrm{dm}^{-3}\right)$ & 0,40 & 3,00 \\
\hline $\mathrm{Al}\left(\mathrm{cmol}_{\mathrm{c}} \mathrm{dm}^{-3}\right)$ & 0,01 & 0,00 \\
\hline $\mathrm{H}+\mathrm{Al}\left(\mathrm{cmol}_{\mathrm{c}} \mathrm{dm}^{-3}\right)$ & 2,89 & 0,00 \\
\hline $\mathrm{Na}\left(\mathrm{cmol}_{\mathrm{c}} \mathrm{dm}^{-3}\right)$ & 0,05 & 0,67 \\
\hline $\mathrm{K}\left(\mathrm{cmol}_{\mathrm{c}} \mathrm{dm}^{-3}\right)$ & 0,15 & 0,68 \\
\hline $\mathrm{P}_{\text {Mehlich }}\left(\mathrm{mg} \mathrm{dm}^{-3}\right)$ & 3,28 & 28,50 \\
\hline $\mathrm{P}_{\text {Olsen }}\left(\mathrm{mg} \mathrm{dm}^{-3}\right)$ & 2,98 & 15,70 \\
\hline $\mathrm{P}_{\mathrm{rem}}\left(\mathrm{mg} \mathrm{L}^{-1}\right)$ & 46,60 & 35,00 \\
\hline $\operatorname{CTC}^{1}\left(\mathrm{cmol}_{\mathrm{c}} \mathrm{dm}^{-3}\right)$ & 4,39 & 16,40 \\
\hline $\mathrm{SB}^{2}\left(\mathrm{cmol}_{\mathrm{c}} \mathrm{dm}^{-3}\right)$ & 1,50 & 16,40 \\
\hline $\mathrm{V}^{3}(\%)$ & 34,20 & 100 \\
\hline Areia $\left(\mathrm{g} \mathrm{kg}^{-1}\right)$ & 810 & 252 \\
\hline Silte $\left(\mathrm{g} \mathrm{kg}^{-1}\right)$ & 42,0 & 500 \\
\hline Argila $\left(\mathrm{g} \mathrm{kg}^{-1}\right)$ & 148 & 248 \\
\hline $\mathrm{Ds}^{4}\left(\mathrm{~g} \mathrm{~cm}^{-3}\right)$ & 1,68 & 1,40 \\
\hline $\mathrm{Dp}^{5}\left(\mathrm{~g} \mathrm{~cm}^{-3}\right)$ & 2,43 & 2,55 \\
\hline
\end{tabular}

${ }^{1}$; Capacidade de Troca Catiônica; ${ }^{2}$ Soma de Base; ${ }^{3}$ Saturação por Base ; ${ }^{4}$ Densidade do Solo e ${ }^{5}$ Densidade de Partícula

\section{Produção de Biofertilizante}

O biofertilizante foi produzido com adição de enxofre, inoculado com Acidithiobacillus. A bactéria foi cultivada em meio específico $9 \mathrm{~K}$ em Erlenmeyers de $2000 \mathrm{~mL}$, contendo $1.000 \mathrm{~mL}$ de meio, colocados em agitação a $150 \mathrm{rpm}$, por 5 dias a $28-30{ }^{\circ} \mathrm{C}$. O material foi esterilizado a $120^{\circ} \mathrm{C}$, por 30 minutos, em autoclave horizontal. A adição de Acidithiobacillus foi efetuada da seguinte forma: para cada camada com $1.000 \mathrm{~kg}$ de rocha (fosfatada ou potássica), foi realizada a mistura homogênea com enxofre (100 kg) em quatro camadas. Em seguida, adicionou-se a cultura de Acidithiobacillus diluída em água filtrada, na proporção de 1,5 L para cada $10 \mathrm{~L}$ de água. Antes da adição do biofertilizante, o canteiro foi revestido com lona plástica, com a finalidade de evitar acúmulo de água e manter a bactéria no escuro para ativar o processo da produção de ácido sulfúrico. Diariamente o biofertilizante foi irrigado para a manutenção da umidade próxima à capacidade de campo e recoberto com lona de polietileno, durante o período de incubação (60 dias). Depois de produzido, o biofertilizante foi colocado para secagem em temperatura ambiente, peneirado, ensacado e armazenado (LIMA et al. 2007).

Depois, realizou-se as análises químicas do biofertilizante, da rocha fosfatada como também do húmus de minhoca de acordo com metodologia preconizada pela Embrapa (1999), cujos resultados estão apresentados na Tabela 2. As determinações foram executadas em amostras compostas, com coletas em cada cinco sacos do biofertilizante, da rocha moída e do húmus de minhoca totalizando seis repetições.

\section{Condução do experimento}

As doses dePeaadubaçãodoN, Kemicronutrientes foram previamente calculadas, de acordo com as necessidades da cultura do melão, segundo o Manual de Recomendação do Estado de Pernambuco (COMISSÃO ESTADUAL DE FERTILIDADE DO SOLO, 2008). As doses de $\mathrm{P}$ foram adicionadas 30 dias antes do plantio em covas com $10 \mathrm{~cm}$ de profundidade, juntamente com as demais fontes. Utilizou-se o Cloreto de Potássio (KCl) como fonte de $\mathrm{K}, 160 \mathrm{~kg} \mathrm{ha}^{-1}$ de $\mathrm{K}_{2} \mathrm{O}$, e para a adubação nitrogenada o húmus de minhoca (TAB. 1), na dose de $40 \mathrm{~kg} \mathrm{ha}^{-1}$. A adubação com micronutrientes foi realizada através de uma mistura comercial tendo boro como referência para os cálculos $\left(4 \mathrm{~kg} \mathrm{ha}^{-1}\right)$, aplicados via fertirrigação. Durante o decorrer dos três ciclos do experimento, houve adubações complementares por meio da fertirrigação para manutenção da cultura (STAMFORD et al., 2004b).

Tabela 2 - Análise química do biofertilizante, rocha fosfatada e húmus $(\mathrm{n}=6)$

\begin{tabular}{|c|c|c|c|c|c|c|c|c|c|}
\hline \multirow{2}{*}{ Fertilizantes } & $\mathrm{pH}$ & $\mathrm{pH}$ & $\mathrm{pH}$ & $\mathrm{P}$ & $\mathrm{K}$ & $\mathrm{Na}$ & $\mathrm{Ca}$ & $\mathrm{Mg}$ & $\mathrm{N}$ \\
\hline & $\left(\mathrm{H}_{2} \mathrm{O}\right)$ & $(\mathrm{KCl})$ & $\left(\mathrm{CaCl}_{2}\right)$ & \multicolumn{6}{|c|}{ 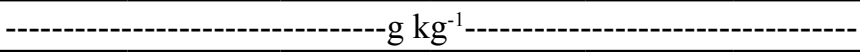 } \\
\hline Biofertilizante & 3,10 & 2,83 & 3,04 & 44,99 & 0,10 & 0,50 & 2,75 & 1,00 & 0,00 \\
\hline Rocha Fosfatada & 6,96 & 6,89 & 6,97 & 0,40 & 0,00 & 0,70 & 2,00 & 0,00 & 0,00 \\
\hline Húmus & 6,38 & 6,32 & 6,24 & 0,80 & 0,30 & 0,10 & 0,00 & 0,00 & 8,70 \\
\hline
\end{tabular}


Foi utilizado a cultivar híbrida Mandacaru (Sakata), após a realização do teste de germinação, com 12 DAP realizou-se o transplante das mudas. As plantas foram mantidas tutoradas. Durante os três ciclos, realizouse a irrigação com água destilada, duas vezes por dia, sendo que a quantidade de água variou de acordo com a capacidade de campo e o ponto de murcha permanente de cada solo, e com a fase de desenvolvimento da cultura. Os três ciclos não foram conduzidos até o fim, ou seja, 60 DAP, em virtude da baixa taxa de fecundação dos frutos, explicada pela ausência de insetos (abelhas) dentro da casa de vegetação. Desta maneira, as plantas foram colhidas após o final do florescimento e início da frutificação, aos 45 DAP.

\section{Análises realizadas}

As plantas foram cortadas a $1 \mathrm{~cm}$ do solo e pesada imediatamente para obtenção da massa fresca da parte aérea (MFPA), posteriormente foram levadas à estufa com circulação de ar forçada, a $65^{\circ} \mathrm{C}$ até obter peso constante. Após esse procedimento, a matéria seca da parte aérea (MSPA) foi triturada e analisada quanto ao $\mathrm{Ca}, \mathrm{Mg}, \mathrm{Na}, \mathrm{K}$ e $\mathrm{P}$, por meio de digestão nitro-perclórica, numa relação $(1: 3)$.

As amostras de solo foram coletadas nos tratamentos do terceiro ciclo e depois de secas, destorroadas e peneiradas em malha de $2 \mathrm{~mm}$ foram determinados os seguintes atributos químico: $\mathrm{pH}$ em água $(1: 2,5), \mathrm{pH}$ em $\mathrm{KCl} 1 \mathrm{~mol} \mathrm{~L}^{-1}$ e pH em $\mathrm{CaCl}_{2} 0,01 \mathrm{~mol} \mathrm{~L}^{-1} ; \mathrm{Ca}^{+2}$ utilizando como extrator o $\mathrm{KCl} 1 \mathrm{~mol} \mathrm{~L}^{-1}$ (EMBRAPA, 1997); P disponível obtido pelos extratores Mehlich-1 $\left(\mathrm{HCl} 0,05 \mathrm{~mol} \mathrm{~L}^{-1}+\mathrm{H}_{2} \mathrm{SO}_{4} 0,0125 \mathrm{~mol} \mathrm{~L}^{-1}\right)$, Mehlich-3 $\left(\mathrm{NH}_{4} \mathrm{~F} 0,0015 \mathrm{~mol} \mathrm{~L}^{-1}+\mathrm{CH}_{3} \mathrm{COOH} 0,2 \mathrm{~mol} \mathrm{~L}^{-1}+\mathrm{NH}_{4} \mathrm{NO}_{3}\right.$ $0,25 \mathrm{~mol} \mathrm{~L}^{-1}+\mathrm{HNO}_{3} 0,013 \mathrm{~mol} \mathrm{~L}^{-1}+$ EDTA $0,001 \mathrm{~mol} \mathrm{~L}^{-1}$ ) e Olsen (bicarbonato de sódio $0,5 \mathrm{~mol} \mathrm{~L}^{-1}, \mathrm{pH}$ ajustado para $8,5)$, numa relação solo extrator de $1: 10\left(5 \mathrm{~cm}^{3}\right.$ de TFSA e $50 \mathrm{~mL}$ da solução extratora), agitando-se por 5 minutos em agitador horizontal, deixando-se decantar durante 16 horas. A determinação do P foi realizada conforme descrito em Braga e Defelipo (1974).

\section{Análise estatística}

Foram realizadas análises de variância para MFPA, MSPA e para os nutrientes ( $\mathrm{Ca}, \mathrm{Mg}, \mathrm{Na}, \mathrm{K}$ e $\mathrm{P}$ ) na parte aérea do melão, no terceiro cultivo. Para este mesmo ciclo, foi realizado análise de variância para todos os atributos químicos avaliados do solo. Ajustaram-se equações de regressão do $\mathrm{P}$ recuperado pelo extrator Olsen, bem como para MSPA do teor de $\mathrm{P}$ na planta, em função do $\mathrm{P}$ aplicado. As análises estatísticas foram efetuadas com o auxílio do SAEG versão 9.0 (SAEG, 2005).

\section{Resultados e discussão}

A fertilização com $\mathrm{P}$ apresentou resposta significativa $(\mathrm{p}<0,05)$, após três cultivos com melão (TAB. 3), entretanto, houve diferença $(p<0,05)$ entre as fontes de fósforo para MFPA, onde o biofertilizante obteve maiores valores médio de 87,35 e 111,37 g para o Latossolo e Neossolo, respectivamente, não diferenciando estatisticamente do supertriplo. O biofertilizante fosfatado também proporcionou o maior acúmulo de massa seca, 11,66 e 17,91 g para o Latossolo e Neossolo, respectivamente. Porém, não houve diferença estatística entre os demais fertilizantes fosfatados. Por outro lado, os tratamentos com rocha fosfatada e superfosfato triplo não apresentaram diferença significativa entre si.

Tabela 3 - Produção de matéria fresca (MFPA), matéria seca (MSPA) e conteúdos de $\mathrm{Ca}, \mathrm{Mg}, \mathrm{Na}, \mathrm{K}$ e P na parte aérea do meloeiro nas diferentes fontes de fósforo nos solos estudados, em casa de vegetação

\begin{tabular}{|c|c|c|c|c|c|c|c|c|}
\hline \multirow{2}{*}{ Solo } & \multirow{2}{*}{ Fonte } & \multicolumn{7}{|c|}{ Variáveis } \\
\hline & & MFPA & MSPA & $\mathrm{Ca}$ & $\mathrm{Mg}$ & $\mathrm{Na}$ & $\mathrm{K}$ & $\mathrm{P}$ \\
\hline & & \multicolumn{2}{|c|}{ 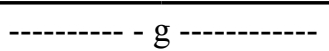 } & \multicolumn{5}{|c|}{ - } \\
\hline \multirow{3}{*}{ Latossolo Amarelo } & supertriplo & $81,85 \mathrm{ab}$ & $9,34 \mathrm{a}$ & $82,85 \mathrm{a}$ & $14,52 \mathrm{~b}$ & $1,98 \mathrm{~b}$ & $5,45 \mathrm{a}$ & $2,47 \mathrm{~b}$ \\
\hline & biofertilizante & $87,35 \mathrm{a}$ & $11,66 \mathrm{a}$ & $109,03 \mathrm{a}$ & $20,56 \mathrm{a}$ & $2,92 \mathrm{a}$ & $6,65 \mathrm{a}$ & $5,20 \mathrm{a}$ \\
\hline & rocha fosfatada & $76,45 \mathrm{~b}$ & $9,76 \mathrm{a}$ & $86,09 \mathrm{a}$ & $20,16 \mathrm{ab}$ & $2,07 \mathrm{~b}$ & $6,02 \mathrm{a}$ & $2,75 \mathrm{~b}$ \\
\hline \multirow{3}{*}{ Neossolo Flúvico } & supertriplo & $105,23 \mathrm{ab}$ & $15,91 \mathrm{a}$ & $181,50 \mathrm{~b}$ & $45,95 \mathrm{a}$ & $2,76 \mathrm{a}$ & $9,08 \mathrm{a}$ & $5,39 \mathrm{~b}$ \\
\hline & biofertilizante & $111,37 \mathrm{a}$ & $17,91 \mathrm{a}$ & $245,50 \mathrm{a}$ & $47,03 \mathrm{a}$ & $3,01 \mathrm{a}$ & $10,06 \mathrm{a}$ & $9,45 \mathrm{a}$ \\
\hline & rocha fosfatada & $101,92 \mathrm{~b}$ & $16,96 \mathrm{a}$ & $205,32 \mathrm{ab}$ & $39,21 \mathrm{~b}$ & $2,54 \mathrm{a}$ & $9,10 \mathrm{a}$ & $6,20 \mathrm{~b}$ \\
\hline $\mathrm{CV}^{1}(\%)$ & 10,57 & 24,31 & 28,49 & 25,66 & 32,07 & 28,84 & 24,84 & \\
\hline
\end{tabular}

Médias seguidas de mesma letra minúsculas nas colunas não diferem estatisticamente pelo teste de Tukey a 5\% de probabilidade dentro de cada solo; ${ }^{1}$ Coeficiente de variação 
Sobre o ajuste das equações na MSPA do meloeiro, o Latossolo, foi melhor ajustado com a função quadrática para o superfosfato triplo e, lineares para o biofertilizante fosfatado e rocha fosfatada. No Neossolo, o modelo de função quadrática foi utilizado para as fontes superfosfato triplo e biofertilizante fosfatado, e para rocha fosfatada o modelo ajustado foi o de raiz quadrada (FIG. 1).

Apesar de o fósforo ser mais influente na fase reprodutiva do meloeiro (AMORIM et al., 2008;

\section{LATOSSOLO AMARELO}
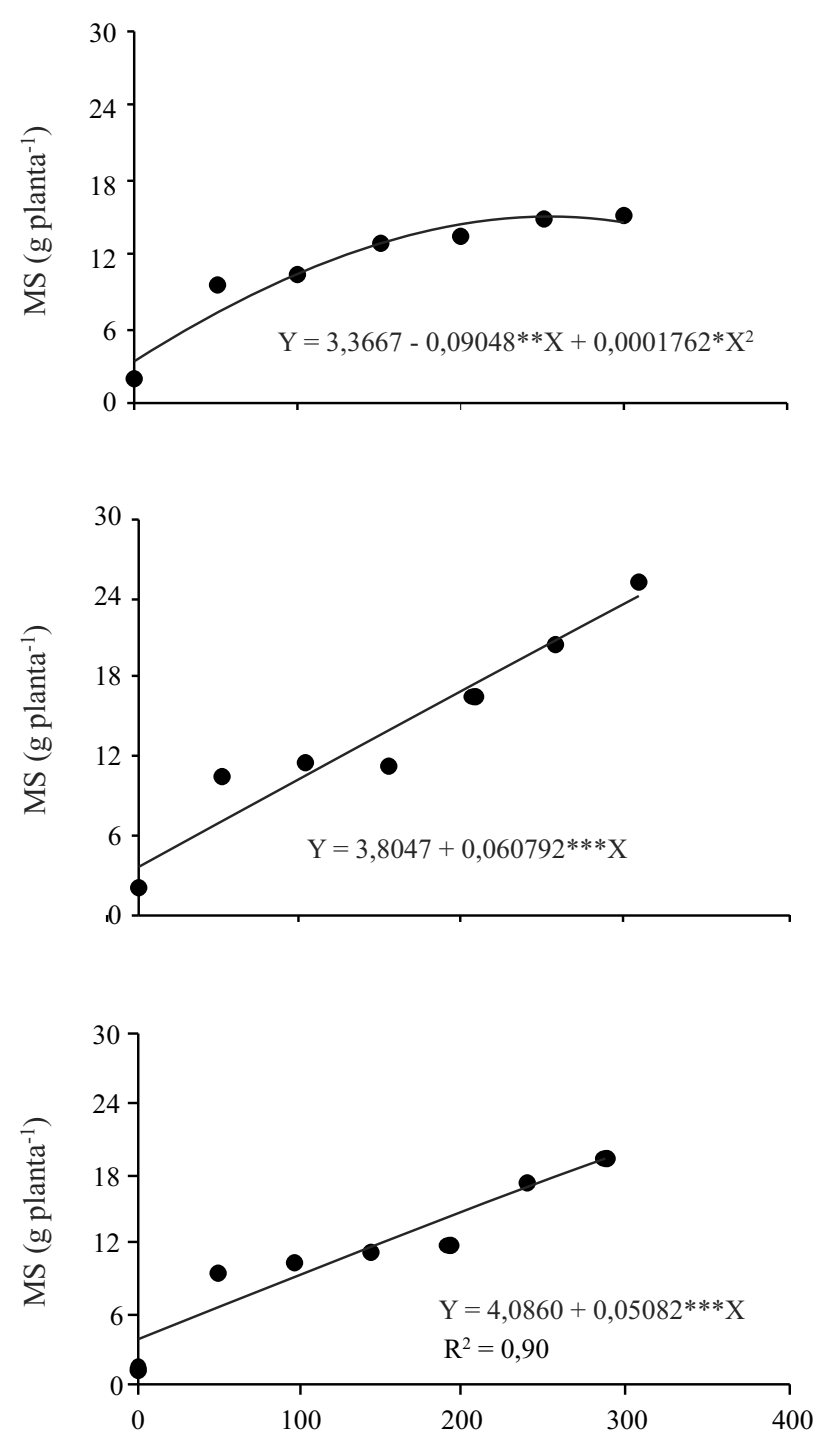

$\mathrm{P}\left(\mathrm{kg} \mathrm{ha}^{-1}\right)$
NEGREIROS et al., 2003 ), nessa pesquisa, pôde-se constatar ganho de MSPA em função do aumento das doses aplicadas dos fertilizantes (FIG. 1).

Avaliando o uso do biofertilizante de rochas fosfatada, Moura et al. (2007), constatou ganho de MSPA no meloeiro cultivado em Argissolo Acinzentado no Vale do São Francisco, Stamford et al. (2006) com canadeaçúcar (Saccharum officinarum) em solo de tabuleiro da Zona da Mata de Pernambuco e Lima et al. (2007), com
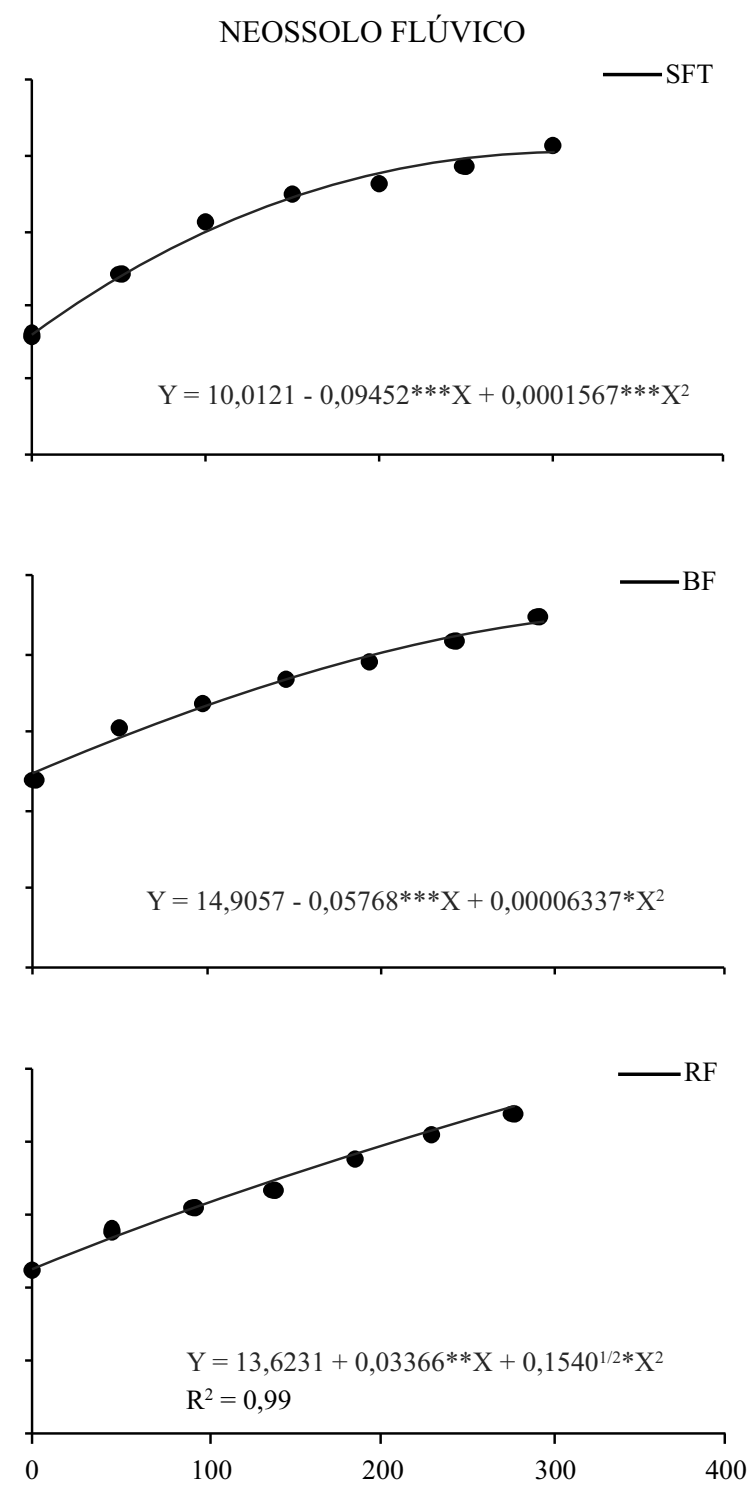

$\mathrm{P}\left(\mathrm{kg} \mathrm{ha}^{-1}\right)$

$* * *, * *, \mathrm{e}^{\circ}$ - Significativos a 0,$1 ; 1 ; 5$ e $10 \%$, respectivamente. - SFT (super fosfato triplo), $-\mathrm{BF}$ (biofertilizande fosfatado) e-RF (rocha fosfatada)

Figura 1 - Produção de matéria seca da parte aerea das plantas (MSPA) em função das doses de fósforo aplicadas para o superfosfato triplo (SFT), biofertilizante fosfatado (BF) e rocha fosfatada (RF) no terceiro cultivo do meloeiro para o Latossolo amarelo e Neossolo flúvico 
alface cultivado sob Latossolo Amarelo no sertão Cariri do Ceará. Stamford et al. (2005), usando rocha fosfatada natural (apatita de Gafsa) com adição de enxofre, com e sem inoculação com Acidithiobacillus, constataram aumento na produção de biomassa da parte aérea de sabiá (Mimosa caesalpiniifolia).

Com relação aos acúmulos de nutrientes pela cultura pode-se observar que não houve diferença significativa no acúmulo de Ca e K, porém no Latossolo a fonte $\mathrm{BF}$ foi a que proporcionou o maior teor desses elementos na planta. Já para o Neossolo, houve diferença significativa para o $\mathrm{Ca}$ quando utilizado o $\mathrm{BF}$, o qual, proporcionou um maior estoque desse macronutriente. $\mathrm{O} \mathrm{K}$, entretanto, se comportou de forma semelhante ao $\mathrm{Ca}$ em ambos os solos. Para os elementos $\mathrm{Mg}$ e $\mathrm{Na}$, observou-se diferença estatística com a adição do BF, com o maior acúmulo desses elementos na planta em ambos os solos, exceto para o Na no Neossolo que não apresentou diferença estatística (TAB. 3). No entanto, Belfort (1985) ao trabalhar com melão em um Latossolo Vermelho Amarelo encontrou valores médios para $\mathrm{Mg}$ acumulado na parte aérea do meloeiro, de $19 \mathrm{mg}$ por planta, no final do ciclo da cultura.

$\mathrm{O}$ acúmulo de $\mathrm{P}$ na planta apresentou diferença estatística para as fontes e em ambos os solos. As plantas acumularam $\mathrm{P}$ na seguinte ordem de tratamentos: $\mathrm{BF}>\mathrm{RF}>\mathrm{SFT}$, nos dois solos estudados (TAB. 3). Esse efeito observado para a rocha fosfatada pode ter sido em função de que a mesma foi usada com adição de enxofre elementar, sem inoculação com Acidithiobacillus. Provavelmente deve ter havido participação efetiva das bactérias oxidantes do enxofre nativas do solo, que contribuem na solubilização de P (SANTOS, 2002), promovendo assim o aumento no desenvolvimento da planta. Resultados semelhantes foram obtidos por Stamford et al. (2004a, 2004b e 2005). Na cultura da cana-de-açúcar, em solo de tabuleiro de Pernambuco com baixos teores de P e K disponível, Lima (2005) também verificou efeito positivo de biofertilizantes com $\mathrm{P}$ e $\mathrm{K}$, comparados com fertilizantes convencionais $(\mathrm{SFT}+\mathrm{KCl})$ e com rochas fosfatadas e potássicas.

Na Figura 2, pode-se evidenciar maior acúmulo de P na planta em função das doses aplicadas dos fertilizantes. Em ambos os solos, os ajustes foram curvilíneos e linear, com parâmetros altamente significativos para as fontes SFT e BF, e RF, respectivamente.

Os valores de $\mathrm{pH}$ em função da fertilização com $\mathrm{P}$ no solo encontram-se na Tabela 4. No Latossolo verificou-se um ligeiro aumento nos valores do pH em água em relação ao inicial ( $\mathrm{pH} 5,40)$, quando aplicados $\mathrm{BF}$, sem diferença significativa para as fontes. O uso de BF inoculado com Acidithiobacillus promoveu liberação de íons $\mathrm{H}^{+}$ (STAMFORD et al., 2002; 2005), sendo essa mudança menos perceptível no Latossolo Amarelo, conseqüência esta, da alta concentração de areia $\left(810 \mathrm{~g} \mathrm{~kg}^{-1}\right)$, baixa concentração de argila $\left(148 \mathrm{~g} \mathrm{~kg}^{-1}\right)$ e da menor CTC deste solo, diferentemente do Neossolo Flúvico, proporcionando desta forma, comportamentos antagônicos.

Para Neossolo Flúvico, observou-se decréscimo do $\mathrm{pH}$ inicial do solo para os tratamentos com aplicação de BF e RF (TAB. 4), isso provavelmente ocorreu em virtude da adição do $\mathrm{S}$ elementar das rochas fosfatadas e da participação efetiva das bactérias oxidantes do enxofre, nativas do solo, contribuindo desta forma para o aumento da acidez.

A aplicação das rochas pode ter ocasionado a acidificação do solo de modo semelhante ao relatado por Villar (2003), que ao trabalhar com lixiviação bacteriana

Tabela 4 - Valores de $\mathrm{pH}\left(\mathrm{H}_{2} \mathrm{O}, \mathrm{KCl}\right.$ e $\left.\mathrm{CaCl}_{2}\right)$ e teores de $\mathrm{Ca}$, $\mathrm{P}$ recuperado por diferentes extratores em função das fontes de fósforo aplicados nos solos estudados no terceiro cultivo de melão, em casa de vegetação

\begin{tabular}{ccccccccc}
\hline \multirow{2}{*}{ Solo } & \multirow{2}{*}{ Fonte } & \multicolumn{7}{c}{ Variáveis } \\
\cline { 3 - 9 } & & $\mathrm{pH}$ & $\mathrm{pH}$ & $\mathrm{pH}$ & $\mathrm{Ca}$ & P Melich-1 & P Olsen & P Melich-3 \\
\cline { 3 - 9 } & supertriplo & $5,62 \mathrm{a}$ & $4,54 \mathrm{a}$ & $4,59 \mathrm{a}$ & $3,08 \mathrm{a}$ & $33,62 \mathrm{c}$ & $16,82 \mathrm{c}$ & $24,53 \mathrm{~b}$ \\
& & $\mathrm{H}_{2} \mathrm{O}$ & $\mathrm{KCl}$ & $\mathrm{CaCl}_{2}$ & $\mathrm{cmol}_{\mathrm{c}} \mathrm{dm}^{-3}$ & $---------\mathrm{mg} \mathrm{dm}^{-3}----------$ \\
\hline \multirow{2}{*}{ Latossolo Amarelo } & biofertilizante & $5,60 \mathrm{a}$ & $4,50 \mathrm{a}$ & $4,57 \mathrm{a}$ & $2,78 \mathrm{a}$ & $48,85 \mathrm{a}$ & $26,57 \mathrm{a}$ & $32,09 \mathrm{a}$ \\
& rocha fosfatada & $5,68 \mathrm{a}$ & $4,46 \mathrm{a}$ & $4,52 \mathrm{a}$ & $2,87 \mathrm{a}$ & $38,32 \mathrm{~b}$ & $24,86 \mathrm{~b}$ & $18,73 \mathrm{c}$ \\
\hline \multirow{2}{*}{ Neossolo Flúvico } & supertriplo & $6,25 \mathrm{a}$ & $5,57 \mathrm{a}$ & $5,89 \mathrm{a}$ & $12,89 \mathrm{a}$ & $25,79 \mathrm{c}$ & $15,51 \mathrm{c}$ & $20,25 \mathrm{c}$ \\
& biofertilizante & $6,33 \mathrm{a}$ & $5,63 \mathrm{a}$ & $6,03 \mathrm{a}$ & $13,17 \mathrm{a}$ & $42,76 \mathrm{a}$ & $26,89 \mathrm{a}$ & $38,12 \mathrm{a}$ \\
& rocha fosfatada & $6,20 \mathrm{a}$ & $5,58 \mathrm{a}$ & $5,99 \mathrm{a}$ & $12,38 \mathrm{a}$ & $39,83 \mathrm{~b}$ & $22,61 \mathrm{~b}$ & $31,43 \mathrm{~b}$ \\
\hline $\mathrm{CV}^{1}(\%)$ & 4,06 & 2,81 & 2,77 & 14,61 & 5,32 & 6,13 & 5,41 &
\end{tabular}

Médias seguidas de mesma letras minúsculas nas colunas não diferem estatisticamente pelo teste de Tukey a 5\% de probabilidade dentro de cada solo. ${ }^{1}$ Coeficiente de variação 
LATOSSOLO AMARELO
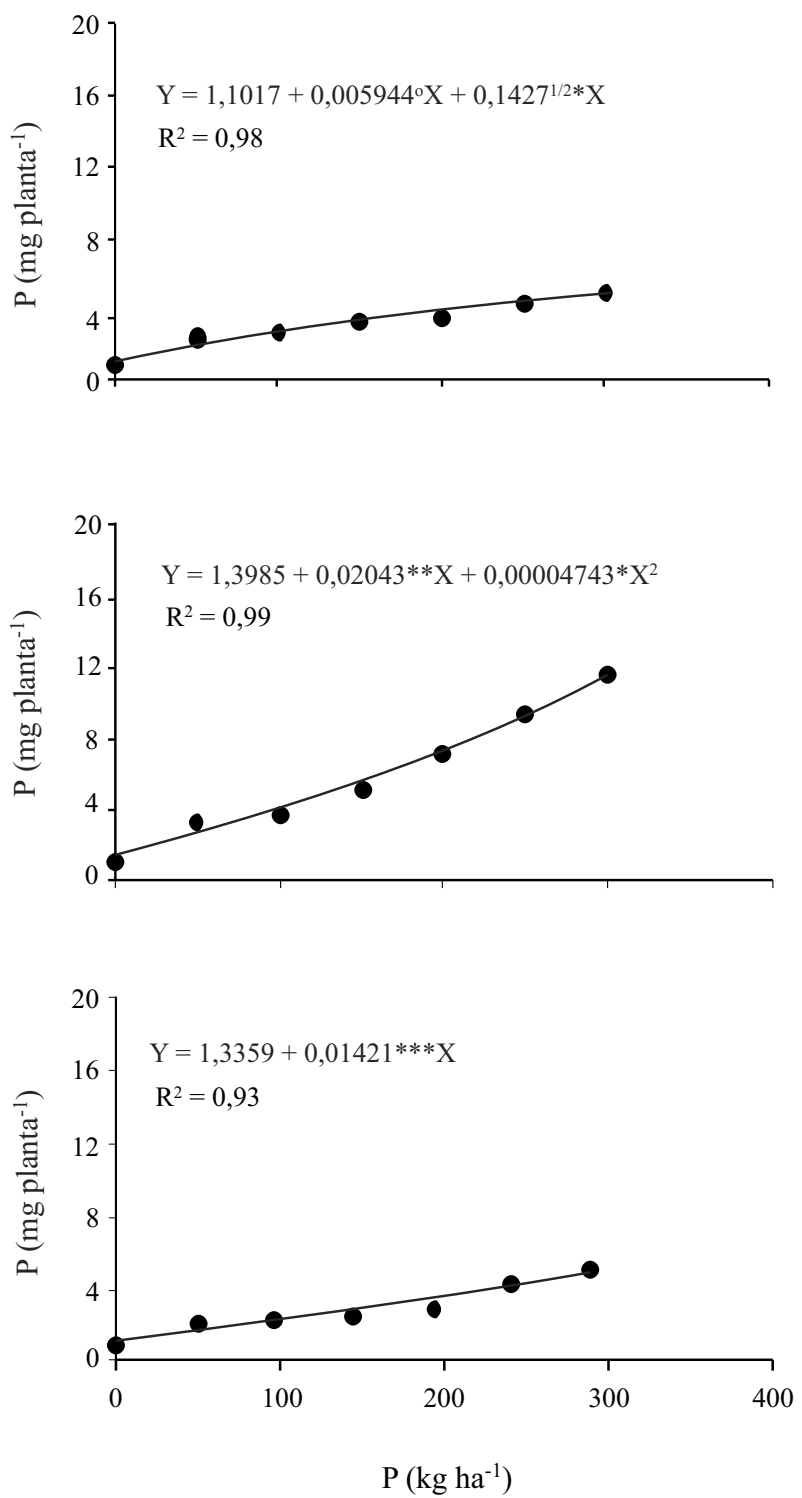

NEOSSOLO FLÚVICO
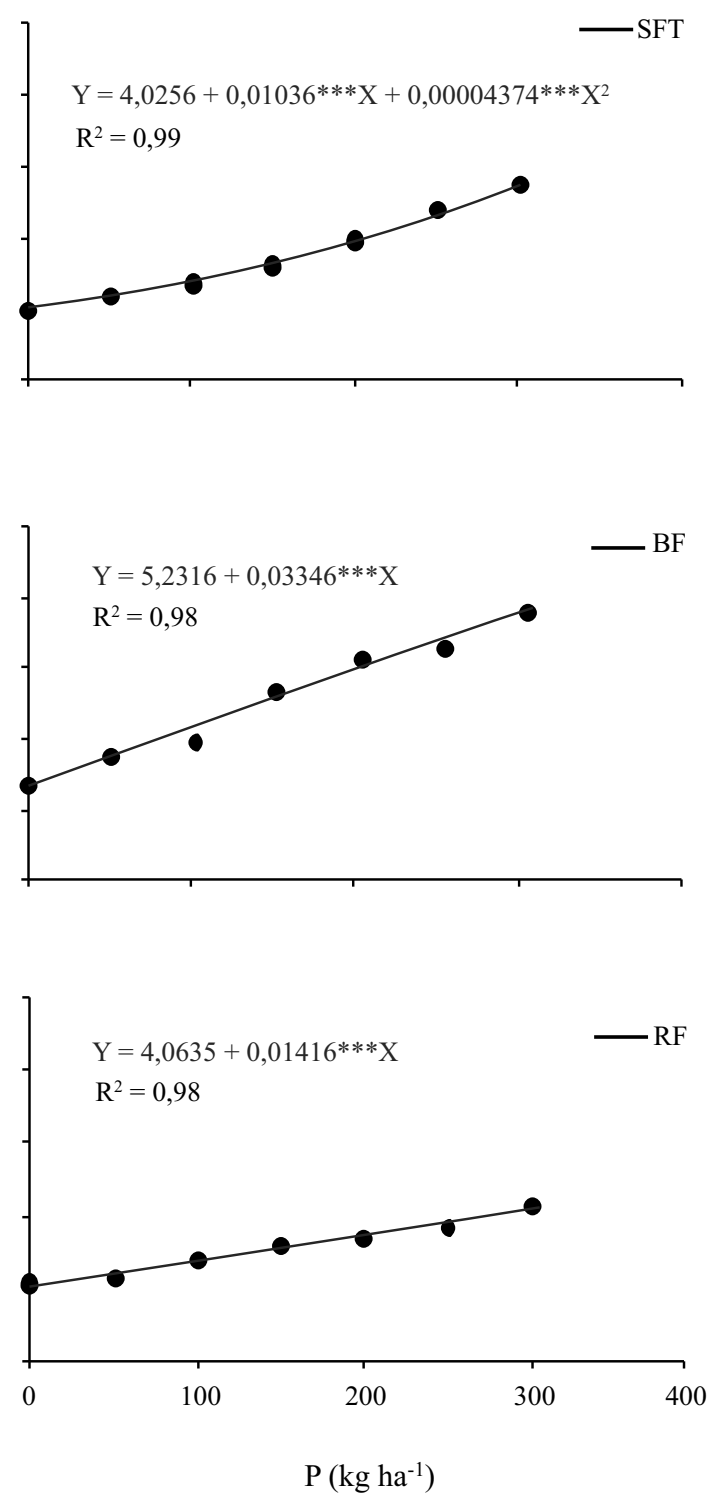

$* * *, * *, * \mathrm{e}^{\circ}$ - Significativos a 0,$1 ; 1 ; 5$ e $10 \%$, respectivamente

Figura 2 - Conteúdo de P acumulado em função das doses de fósforo aplicadas dos fertilizantes para o superfosfato triplo (SFT), biofertilizante fosfatado (BF) e rocha fosfatada (RF) no terceiro cultivo do meloeiro para o Latossolo amarelo e Neossolo flúvico

de metais presentes em lodo de esgoto sanitário sugeriu que a presença da espécie Acidithiobacillus thiooxidans no lodo foi o principal responsável pela acidificação do lodo, cujo $\mathrm{pH}$ foi inferior a 4,0.

Stamford et al. (2002), usando S inoculado com Acidithiobacillus na recuperação de solos salinos sódicos, observaram que a produção de $\mathrm{H}_{2} \mathrm{SO}_{4}$ continua a ocorrer até o consumo total do $\mathrm{S}$ adicionado, chegando a promover a acidificação do solo com redução do $\mathrm{pH}$ inicial de 8,2 para 4,5 com adição de $1,8 \mathrm{t} \mathrm{ha}^{-1}$ de enxofre. Stamford et al. (2005) usando a rocha fosfatada (apatita de Gafsa) com adição de enxofre, com e sem inoculação com Acidithiobacillus, constataram que em solo cultivado com sabiá (Mimosa cesalpiniifolia), ocorreu redução no $\mathrm{pH}$ com e sem inoculação, embora a maior acidez tenha sido observada quando o enxofre foi inoculado com a bactéria.

Com relação ao Ca disponível, constatou-se que não houve diferença estatística entre as fontes de fósforo aplicadas na disponibilidade de $\mathrm{Ca}$ para ambos os solos (TAB. 4). Quanto ao teor de P disponível, verificou-se que o biofertilizante fosfatado e o tratamento com aplicação das rochas fosfatadas apresentaram os teores mais elevados de 
P no solo, independentemente do extrator. Houve diferença significativa para o tratamento com aplicação de fertilizantes convencionais (SFT) que apresentaram teores menores de $\mathrm{P}$ disponível. Esses resultados evidenciam que fertilizantes mais solúveis tem seu efeito reduzido ao longo do tempo.

Na Figura 3, pode-se ratificar a disponibilidade do $\mathrm{P}$ recuperado nos solos estudados por meio de equações ajustadas apenas para o extrator Olsen, devido este ter apresentado melhor correlação com a planta no primeiro cultivo. Para Alvarez V. et al. (2000), é necessário que os teores de $\mathrm{P}$ extraídos do solo correlacionem-se com a absorção desse nutriente pelas plantas para que o extrator seja recomendado. No entanto, nos estados do Nordeste, é mais comum a ocorrência de solos menos ácidos do que nas outras regiões do País, o que favorece a formação de compostos pouco solúveis de fosfato de cálcio $(\mathrm{P}-\mathrm{Ca})$ e, conseqüentemente, diminui a aplicabilidade do extrator Mehlich-1 (AMORIM et al., 2008; BOMFIM et al., 2004).
LATOSSOLO AMARELO
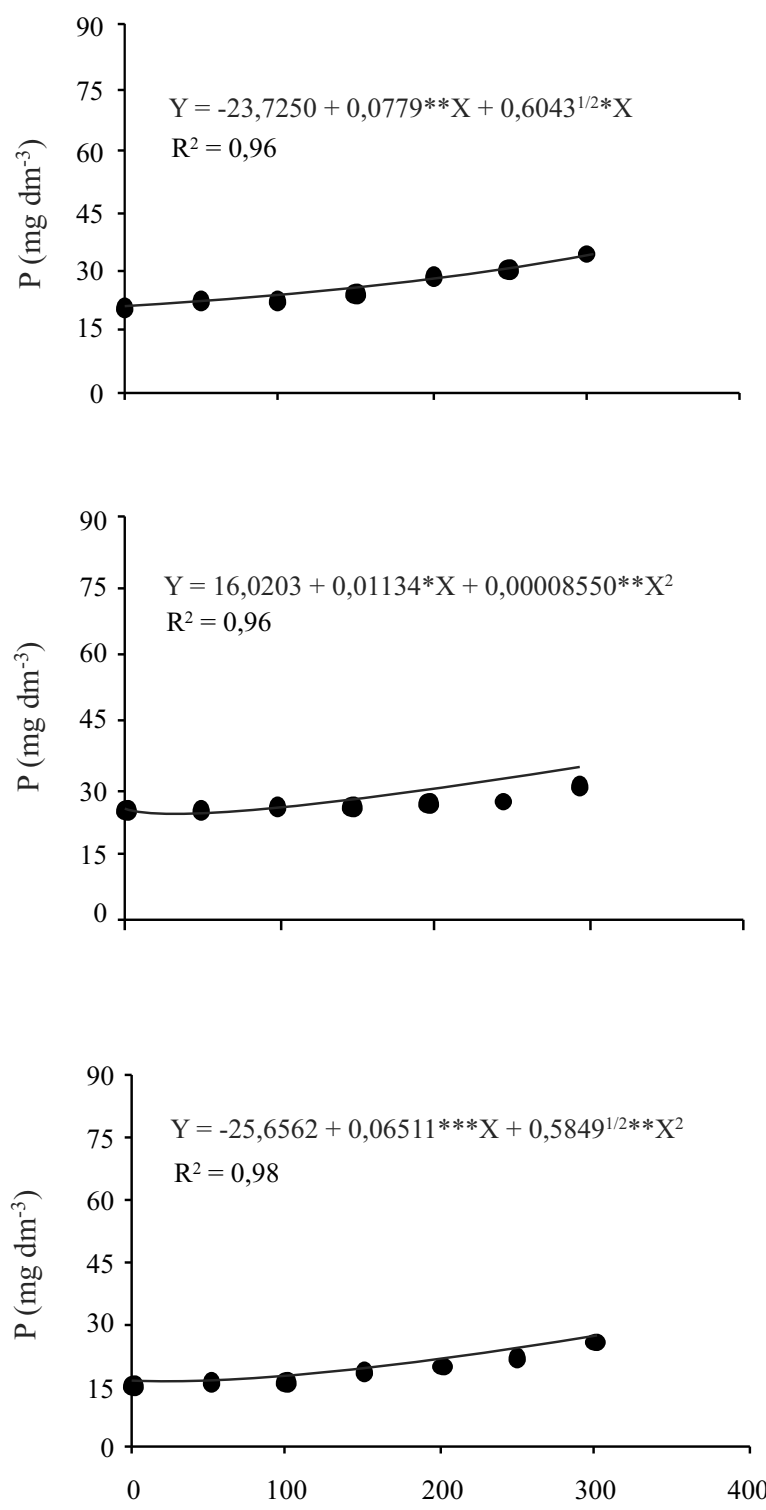

$\mathrm{P}\left(\mathrm{kg} \mathrm{ha}^{-1}\right)$

\section{NEOSSOLO FLÚVICO}
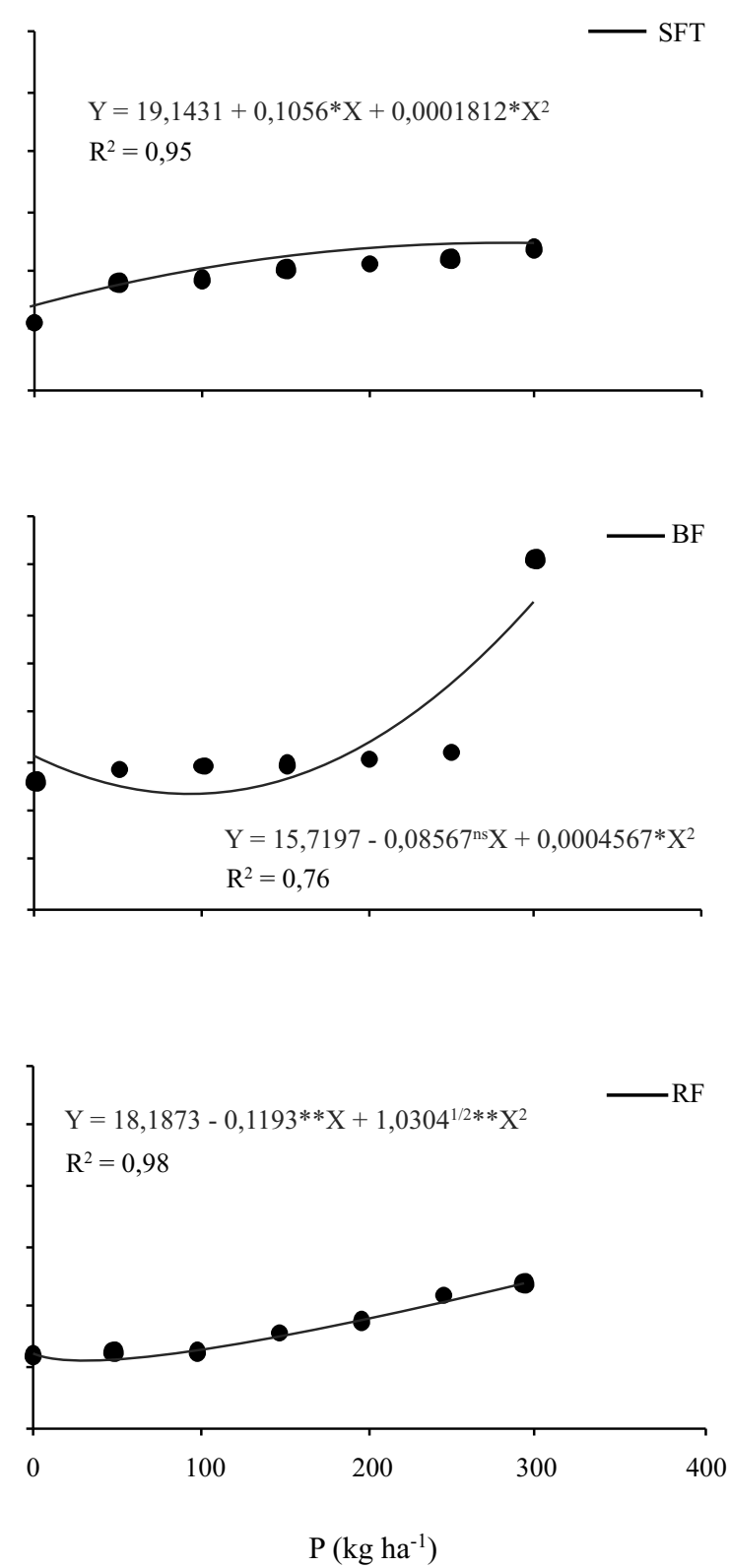

$* * *, * *, * \mathrm{e}^{\circ}$-Significativos a 0,$1 ; 1 ; 5$ e $10 \%$, respectivamente

Figura 3 - P recuperado pelo extrator Olsen em função das doses de fósforo aplicadas para o superfosfato triplo (SFT), biofertilizante fosfatado $(\mathrm{BF})$ e rocha fosfatada $(\mathrm{RF})$ no terceiro cultivo do meloeiro para o Latossolo amarelo e Neossolo flúvico 
Assim, vale ressaltar, que para a preparação do biofertilizante é utilizado um mineral com abundância em fosfato de cálcio, a apatita. As equações ajustaramse melhor com modelos quadráticos em todas as fontes e solos estudados. Em ambos os solos o BF e a RF proporcionaram maiores disponibilidades de $\mathrm{P}$ no solo em função das doses aplicadas, com destaque para BF no Neossolo, onde ocorreu maior disponibilidade de P.

De acordo com Nahas (2002) a adição de fertilizantes como o STF, aumenta significativamente o número de bactérias produtoras de fosfatase alcalina em comparação com adição de fosfato natural. No entanto, uma possível explanação para a diferença observada, no presente trabalho, entre o biofertilizante e os fertilizantes convencionais pode ser em função da presença de Acidithiobacillus que contribuiu para uma maior solubilidade de fósforo no solo, em função do aumento da acidez como descrito por He et al. (1996).

Santos (2002) e Stamford et al. (2003) observaram efeito positivo do fosfato de Gafsa com adição de $\mathrm{S}$ inoculado com Acidithiobacillus no acúmulo de $\mathrm{P}$ na parte aérea e no teor de P disponível em solo cultivado com sabiá (Mimosa caesalpiniifolia) e jacatupé (Pachyrhizus erosus), respectivamente. Stamford et al. (2004a) verificaram efeito do biofertilizante produzido com rocha fosfatada (fosfato de Irecê) inoculado com Acidithiobacillus, no P total acumulado em caupi (Vigna unguiculata L. Walp) e no $\mathrm{P}$ total no solo, com valores mais elevados do que os obtidos com superfosfato triplo.

É bastante conhecido que no solo, o P encontra-se sujeito a inúmeros processos biogeoquímicos que alteram sua disponibilidade. Entre esses processos, destaca-se a solubilidade de fosfatos por fungos micorrízicos, que disponibilizam nutrientes para as plantas como relatado por Whitelaw (2000). Diversos microrganismos do solo, incluindo bactérias e fungos, possuem capacidade para solubilizar fosfatos por meio de diferentes mecanismos, especialmente pela produção de ácidos (RODRIGUES; FRAGA, 1999; SILVA FILHO; VIDOR, 2000; WHITELAW, 2000). Silva filho e Vidor (2000) estudando a solubilização de fosfatos naturais por microrganismos observaram que a produção de ácidos é um dos mecanismos mais utilizado pelos microrganismos nesta tarefa.

De uma forma geral ficou evidenciada a possibilidade de uso de biofertilizantes produzidos a partir de rochas fosfatadas com adição de $\mathrm{S}$ inoculado com Acidithiobacillus como alternativa aos fertilizantes convencionais solúveis nos cultivos sucessivos. Todavia, a aplicação desses deve ser realizada com atenção às técnicas científicas, devido ao seu efeito como fertilizante ser diferenciado em solos com características distintas.

\section{Conclusão}

Os fertilizantes superfosfato triplo, biofertilizante de rocha fosfatada e rocha fosfatada não apresentaram diferenças significativas na produção de matéria seca, porém o biofertilizante foi o que mais disponibilizou P nos dois solos estudados após três ciclos da mesma cultura, isso evidencia o efeito residual dessa fonte, a qual torna-se uma alternativa para adubação fosfatada.

\section{Referências}

AMORIM L. B. et al. Disponibilidade de fósforo em Neossolo Quartzarênico cultivado com melão. Caatinga, v. 21, n. 03, p. 141-146, 2008.

ARAÚJO, F. F. et al. Desenvolvimento do milho e fertilidade do solo após aplicação de lodo de curtume e fosforita. Revista Brasileira de Engenharia Agrícola e Ambiental, v. 12, n. 05, p. 507-511, 2008.

ALVAREZ V., V.H.; NOVAIS, R.F.; DIAS, L.E.; OLIVEIRA, J.A. Determinação e uso do fósforo remanescente. Viçosa, Sociedade Brasileira de Ciência do Solo, v.25, p.27-33. 2000 (Boletim Informativo).

BELFORT, C. C. Acumulação de matéria seca e recrutamento de nutrientes em melão (Cucumis melo $\mathrm{L}$. cv. Valenciano Amarelo CAC) cultivado em Latossolo Vermelho Amarelo em Presidente Venceslau-SP. 1985, 72 f. Tese (Doutorado em Agronomia, área de Solos e nutrição de plantas) - Escola Superior de Agricultura Luis de Queiroz, Piracicaba.

BRAGA, J. M.; DEFELIPO, B. V. Determinação espectrofotométrica de fósforo em extratos de solos e plantas. Revista Ceres, v. 113, p. 73-85, 1974.

BONFIM, E. M. S. et al. Níveis críticos de fósforo para Brachiaria brizantha e suas relações com características físicas e químicas em solos de Pernambuco Revista Brasileira de Ciência do Solo, v. 28 n. 02, p. 281-288, 2004.

COMISSÃO ESTADUAL DE FERTILIDADE DO SOLO. Recomendações de adubação para o estado de Pernambuco: $2^{\mathrm{a}}$ aproximação. 3. ed. Recife: Instituto agronômico de Pernambuco, 2008. $212 \mathrm{p}$.

EMPRESA BRASILEIRA DE PESQUISA AGROPECUÁRIA (EMBRAPA). Manual de análises químicas de solos, plantas e fertilizantes. Brasília: Comunicação para transferência de tecnologia, $1999.370 \mathrm{p}$.

EMPRESA BRASILEIRA DE PESQUISA AGROPECUÁRIA (EMBRAPA). Manual de Métodos de Análise de solo. 2. ed. Brasília: Centro Nacional de Pesquisa de Solos, 1997. 212 p.

GOEDERT, W. J.; SOUSA, D. M. G. Avaliação preliminar de fosfato com acidulação parcial. Revista Brasileira de Ciência do Solo, v. 10, p. 75-80, 1986.

INSTITUTO BRASILEIRO DE GEOGRAFIA E ESTATÍSTICA (IBGE). Produção Agrícola Municipal 
2006. Disponível em: <http://www.ibge.gov.br/servidor arquivos_est/>. Acesso em: 13 set. 2009.

HE, Z. L. et al. Factors affecting phosphate rock dissolution in acid soil amended with liming materials and cellulose. Soil Science Society of America Journal, v. 60, n. 05, p. 1596-1601, 1996.

LEÃO, A. B. et al. Variabilidade espacial de fósforo em solo do perímetro irrigado Engenheiro Arcoverde, PB. Revista Ciência Agronômica, v. 38, n. 01, p. 1-6, 2007.

LIMA, R. A. Biofertilizantes produzidos com fosfato natural e enxofre inoculado com Acidithiobacillus em solo de tabuleiro com baixo P disponível cultivado com cana-de-açúcar. 2005. 69 f. Dissertação (Mestrado em Ciência do solo) - Universidade Federal Rural de Pernambuco, Recife.

LIMA, R. C. M. et al. Rendimento da alface e atributos químicos de um Latossolo em função da aplicação de biofertilizantes de rochas com fósforo e potássio. Horticultura Brasileira, 25 v. 02, p. 224-229, 2007.

MOURA, P. M. et al.. Eficiência de biofertilizantes de rochas com Acidithiobacillus em melão, no Vale do São Francisco. Revista Brasileira de Ciências Agrárias, v. 02, n. 01, p. 1-7, 2007.

NAHAS, E. Microrganismos do solo produtores de fosfatases em diferentes sistemas agrícolas. Bragantia, v. 61, n. 03, p. 267-275, 2002.

NEGREIROS, M. Z. et al. Cultivo do melão no pólo Rio Grande do Norte/Ceará. Horticultura Brasileira, v. 21, n. 03, p. 1-1. 2003.

RODRÍGUEZ, H.; FRAGA, R. Phosphate solubilizing bacteria and their role in plant growth promotion. Biotechonology Advances, v. 17, n. 04/05, p. 319-339, 1999.

SISTEMA PARA ANÁLISES ESTATÍSTICAS (SAEG). Sistema para análises estatísticas. Versão 9.0. Viçosa: Fundação Arthur Bernardes, 2005.

SANTOS, K. S. Atuação de fosfato natural com adição de enxofre com Acidithiobacillus na solubilização de fósforo e no desenvolvimento de sabiá (Mimosa caesalpiniifolia) em solo de tabuleiro. 2002. 68 f. Dissertação (Mestrado em Ciências do solo) - Universidade Federal Rural de Pernambuco, Recife.

SILVA FILHO, G. N.; VIDOR, C. Solubilização de fosfatos por microrganismos na presença de fontes de carbono. Revista Brasileira Ciência do Solo, v. 24, n. 02, p. 311-329, 2000.

STAMFORDN.P.etal. Rock biofertilizers with Acidithiobacillus on sugarcane yield and nutrient uptake in a Brazilian soil. Geomicrobiology Journal v. 23, n. 05, p. 261-265, 2006a.

STAMFORD, N. P. et al. Atuação de Acidithiobacillus na solubilização de fosfato natural em solo de tabuleiro cultivado com jacatupé (Pachyrhizus erosus). Revista Brasileira Ciência do Solo, v. 28, n. 01, p. 75-83, 2004a.

STAMFORD, N. P. et al. Biofertilizante de rocha com Acidithiobacillus em solo de tabuleiro cultivado com caupi. Revista Analytica, v. 03, n. 09, p. 48-53, 2004b.

STAMFORD, N. P. et al. Atuação de Biofertilizantes com fosfato natural e Acidithiobacillus em solo de tabuleiro com baixo P disponível. Scientia Agricola, v. 60, n. 04, p. $767-$ 773. 2003.

STAMFORD, N. P. et al. Effect of sulphur inoculated with Acidithiobacillus in a saline soil grown whit leucena and mimosa tree legumes. Bioresource Technology, v. 81, p. 53-59, 2002.

STAMFORD, N. P. et al. Effects of rock phosphate, sulphur with and without Acidithiobacillus and organic by-products on mimosa (Mimosa caesalpiniifolia) grown in a Brazilian tableland soil. Tropical Grasslands, v. 39, n. 04, p. 54-61, 2005.

VILAR, L. D. Estudo da lixiviação bacteriana de metais presentes em lodo de esgoto sanitário. 2003. 129 f. Tese (Doutorado em Biotecnologia) - Universidade Estadual Paulista, Araraquara.

WHITELAW, M. A. Growth promotion of plant inoculated with phosphate-solubilizing fungi. Advances in Agronomy, v. 69, p. 99-151, 2000. 